\title{
ÁREAS VERDES PÚBLICAS URBANAS E SUA RELAÇÃO COM A MELHORIA DA QUALIDADE DE VIDA: UM ESTUDO DE CASO EM UM PARQUE ECOLÓGICO URBANO NA CIDADE DE FORTALEZA (CEARÁ, BRASIL)
}

URBAN PUBLIC GREEN AREAS AND ITS RELATION TO IMPROVEMENT OF QUALITY OF LIFE: A CASE STUDY IN A URBAN ECOLOGICAL PARK IN THE CITY OF FORTALEZA (CEARÁ STATE, BRAZIL)

\section{Sabrina Morais de Lima}

Graduada em Ciências Ambientais pela Universidade Federal do Ceará (UFC). Estudante de Especialização em Planejamento e Gestão Ambiental pela Universidade Estadual do Ceará (UECE).

\section{Danielle Sequeira Garcez}

Bióloga pela Universidade Federal do Rio de Janeiro (UFRJ). Mestre em Biologia de Água Doce e Pesca Interior pelo Instituto Nacional de Pesquisas da Amazônia (INPA). Doutora em Geografia pela UFRJ. Professora adjunta do Instituto de Ciências do Mar (LABOMAR), da UFC.

Endereço para correspondência: Danielle Sequeira Garcez - Avenida da Abolição, 3.207 - Meireles 60165-081 - Fortaleza (CE) - Brasil E-mail: daniellegarcez@ufc.br

Recebido: 22/12/2015

Aceito: $17 / 03 / 2017$

\section{RESUMO}

O presente estudo buscou identificar as funções desempenhadas pelo Parque Ecológico do Rio Cocó como área verde pública urbana de Fortaleza, Ceará, e analisou de que forma essas funções contribuem para a melhoria da qualidade de vida daqueles que utilizam o espaço. Entrevistas realizadas por aplicação de formulários, com 64 usuários do parque, confirmaram a importância dada pelas pessoas às áreas verdes em razão de seu papel para uma boa qualidade de vida. A esta foram associados: "práticas esportivas e atividades físicas"; "segurança pública"; "presença de parques, praças e áreas verdes"; "contato com a natureza"; "educação de qualidade"; "acesso à água potável"; "sucesso nas relações interpessoais"; "bom convívio familiar"; "realização profissional"; e "moradia adequada". Este estudo também revelou a insatisfação dos entrevistados quanto ao número de áreas verdes em Fortaleza, mas o Parque Ecológico do Cocó destacou-se, entre as demais áreas disponíveis, como um espaço almejado dentro da estrutura urbana da cidade.

Palavras-chave: parques urbanos; qualidade ambiental; bem-estar social.

\section{ABSTRACT}

This study aimed at identify the functions of Coco River Ecological Park as urban green area of Fortaleza, Ceará, Brazil, and examined how these functions contribute to increase the quality of life of park users. This research interviewed 64 people about the importance of the Coco River Ecological Park. According to the answers provided, it was confirmed the significance of urban green areas for a good quality of life. The most important items were: "sports and physical activities"; "public security"; "parks, squares and green areas"; "contact with nature"; "quality of education"; "access to potable water"; "success in interpersonal relationships"; "good family relationship"; "professional achievement"; and "adequate dwelling house". This study also revealed the disappointment of the interviewees with the number of green areas in Fortaleza, but the Coco River Ecological Park was highlighted among the other green areas available as a desired space inside the city.

Keywords: urban parks; environmental quality; social welfare. 


\section{INTRODUÇÃO}

A abordagem relacionada às áreas verdes urbanas é bastante complexa em razão das similaridades e da falta de consenso nas diferenciações entre os termos, como "áreas verdes", "áreas livres", "espaços abertos", "sistemas de espaços livres", "arborização urbana" e tantos outros, permitindo várias interpretações e perspectivas de análise. De modo geral, as áreas verdes são definidas como "locais de domínio público com atributos ambientais, fauna e flora, e que são encontradas no meio urbano, como em parques e praças, sendo capazes de propiciar atividades de lazer ao ar livre" (GUZZO, 1999). De acordo com o art. 8, § 1ㅇ, da Resolução CONAMA no 369/2006, considera-se área verde de domínio público "o espaço de domínio público que desempenhe função ecológica, paisagística e recreativa, propiciando a melhoria da qualidade estética, funcional e ambiental da cidade, sendo dotado de vegetação e espaços livres de impermeabilização" (BRASIL, 2006). Essas áreas verdes estão presentes em várias situações: em áreas de preservação permanente (APP); nos canteiros centrais; nas praças, parques, florestas e unidades de conservação (UC) urbanas; nos jardins institucionais; e nos terrenos públicos não edificados (Ministério do Meio Ambiente). A Lei $n^{\circ} 9.985$, de 8 julho de 2000, que institui o Sistema Nacional de Unidades de Conservação (SNUC), apresenta a definição de "parque" - área verde urbana considerada neste estudo - como categoria de unidade de conservação que compreende o grupo de Unidades de Proteção Integral e tem como objetivo "a preservação de ecossistemas naturais de grande relevância ecológica e beleza cênica, possibilitando a realização de pesquisas científicas e o desenvolvimento de atividades de educação e interpretação ambiental, de recreação em contato com a natureza e de turismo ecológico" (BRASIL, 2000).

Com o atual crescimento acelerado das cidades, paralelo ao inadequado planejamento urbanístico, as áreas verdes naturais estão sendo progressivamente reduzidas na paisagem urbana. As cidades brasileiras, em sua maioria, passam por um período de acentuada urbanização, fator que reflete negativamente na qualidade de vida da população (LOBODA \& DE ANGELIS, 2005).

Nos últimos anos, os estudos sobre áreas verdes vêm sendo associados à questão ambiental urbana. Os tra- balhos de Lima (2007) e Bargos (2010), por exemplo, ambos no estado de São Paulo, abordam a importância das áreas verdes para a qualidade ambiental. Tal foco sobre os problemas ambientais, sobretudo nas últimas décadas, vem sendo uma constante obrigatória no cotidiano das cidades (LOBODA \& DE ANGELIS, 2005).

Entre as funções das áreas verdes urbanas, Guzzo e Cavalheiro (2000) consideram três principais: ecológica, estética e social. A função ecológica está associada às contribuições da vegetação na composição atmosférica urbana, no equilíbrio solo-clima e na atenuação de níveis de ruído; também se relaciona à composição urbana de fauna e flora e aos serviços ecossistêmicos prestados. A função estética, por sua vez, está ligada ao embelezamento da região em que a área verde está inserida, a partir da diversificação da paisagem. Já a função social está intimamente relacionada com as inúmeras possibilidades de lazer, práticas esportivas, culturais e de sociabilidade que essas áreas oferecem à população.

Além dessas, Andrade (2010) considera que as áreas verdes desempenham funções educativa e psicológica. A função educativa está relacionada com a potencialidade em oferecer o desenvolvimento de atividades extraclasse, por exemplo, programas de educação ambiental. A função psicológica ocorre quando os usuários, em contato direto com os elementos naturais dessas áreas, relaxam, tendo um aumento na sensação de bem-estar.

Nos ecossistemas urbanos, onde as condições naturais se encontram parcial ou completamente alteradas, as áreas verdes desempenham papel fundamental na amenização de problemas ambientais, representando um recurso bastante valioso para a melhoria da qualidade de vida, que está atrelada, ainda, a fatores reunidos na infraestrutura e no desenvolvimento econômico-social (LOBODA \& DE ANGELIS, 2005).

O termo "qualidade de vida" foi rapidamente agregado ao vocabulário popular com várias formas de definição. O senso comum apropriou-se desse termo para resumi-lo em um padrão satisfatório de bem-estar na vida. Entretanto, levando-se em conta as inúmeras dimensões que o seu conceito pode incorporar, a área de 
conhecimento em qualidade de vida ainda se encontra inserida em um contexto de construção de identidade (ALMEIDA et al., 2012). Herculano et al. (2000), na busca de elaborar indicadores para avaliação de qualidade de vida, definem o termo como um conceito interdisciplinar, que agrega condições econômicas, ambientais, científico-culturais e políticas, as quais são construídas de forma coletiva, para que os indivíduos possam externar suas potencialidades.

Contudo, a área de conhecimento em qualidade de vida ainda se encontra em fase de construção. No sentido de valorizar parâmetros mais amplos que a diminuição da mortalidade ou o aumento da expectativa de vida, a compreensão sobre qualidade de vida, atualmente, abrange campos do conhecimento humano, social, biológico, econômico, político, da saúde, entre outros, de forma inter-relacionada. Para Almeida et al. (2012), inúmeros esforços podem ser percebidos na tentativa de definir esse campo de conhecimento, como compreender qualidade de vida a partir de esferas objetivas e subjetivas.

Sob o ponto de vista da esfera objetiva, Almeida et al. (2012) referem-se à busca de uma análise da realidade baseada em elementos quantificáveis e concretos, que podem ser transformados pela ação humana. Sob o ponto de vista da esfera subjetiva, os autores também levam em conta questões de ordem concreta, porém consideram variáveis históricas, culturais e de interpretação individual sobre as condições de bens materiais, relacionando-as a fatores emocionais, a expectativas e à percepção que os indivíduos têm de suas próprias vidas. Nesse caso, são consideradas questões não mensuráveis, como prazer, felicidade e tristeza.

A divisão de esferas de percepção em qualidade de vida busca simplificar a problemática da multidisciplinaridade presente em estudos acerca do tema. Diante de tal perspectiva, foram surgindo novas propostas nos estudos relacionados à qualidade de vida, sendo particularmente relevantes aqueles relativos à vida urbana, a qual está intimamente ligada à qualidade ambiental das cidades. As áreas verdes (como as dos parques urbanos) representam nesses casos, importantes mitigadores dos impactos decorrentes da crescente urbanização no que concerne ao seu papel socioambiental. Além de serem espaços abertos ao público para lazer e socialização, atividades físicas e demais funções recreativas, desempenham funções ecológicas importantes na qualidade ambiental da cidade. De modo geral, o homem age constantemente sobre o meio em que vive a fim de sanar suas necessidades, e, muitas vezes, essas ações afetam direta ou indiretamente - de forma benéfica ou não - a sua própria qualidade de vida. Cada indivíduo percebe e reage de modo particular diante das ações sobre o meio, e, dessa maneira, as respostas ou manifestações a isso são resultado das percepções e formas de respostas às expectativas individuais. Assim, considerar a percepção ambiental a partir das respostas populares configura-se como um importante aliado para o poder público quanto à leitura da realidade social, sendo fundamental para que se possa compreender melhor a inter-relação entre a sociedade e o meio, bem como as expectativas, insatisfações e condutas coletivas (RODRIGUES et al., 2012).

Na década de 1970, Jigme Singye Wangchuck, rei do Butão, elaborou a ideia de economia da felicidade (Happiness Economics) e definiu o conceito conhecido no Brasil como Felicidade Nacional Bruta (FNB). O rei pregava, com base na filosofia budista, que crescimento econômico isolado não deveria ser o objetivo principal da sociedade, mas a integração do desenvolvimento material com o psicológico, o cultural e o espiritual. Além do Butão, outros países já contam com indicadores de bem-estar, como Inglaterra, Canadá e Tailândia. Com base nisso, professores da Fundação Getulio Vargas de São Paulo (FGV-SP), em parceria com o Movimento Mais Feliz e com a rede social MyFunCity, desenvolveram estudos, desde 2012, para criar um índice de Felicidade Interna Bruta (FIB) para o Brasil. A metodologia foi lançada, oficialmente, em março de 2013, e visou a mensurar as atuais necessidades e anseios dos brasileiros de cada região do país para conseguir definir o que é preciso para aumentar o bem-estar da população. O resultado foi o Well Being Brazil (WBB), o Índice de Bem-Estar Brasil. Segundo dados apresentados pela Associação Brasileira de Qualidade de Vida (ABQV), os primeiros resultados do WBB mostraram que a riqueza econômica não é o principal fator de felicidade da população. No mesmo ano, a Organização das Nações Unidas (ONU) realizou o estudo World Happiness Report, incluindo a "felicidade" e levantamentos de "bem-estar subjetivo" ao lado de dados sobre condições econômicas e de saúde, a fim de classificar os países mais 
felizes do mundo; atualmente, o estudo se encontra em sua quinta edição.

Diante do contexto da oferta de áreas verdes públicas urbanas e seus reflexos no bem-estar da população, este estudo teve por objetivo identificar funções ambientais e sociais desempenhadas pelo Parque Ecológico do Rio Cocó, em Fortaleza, Ceará, e a sua relação com a melhoria da qualidade de vida, a partir da percepção ambiental daqueles que o utilizam.

\section{MATERIAL E MÉTODOS}

\section{Área de estudo: Parque Ecológico do Rio Cocó, Fortaleza, Ceará}

A cidade de Fortaleza, localizada no estado do Ceará, passa por uma constante expansão populacional, sofre com rápidas e constantes transformações em relação à verticalização (ALVES, 2013), e é hoje a quinta cidade mais populosa do Brasil, segundo dados do Instituto Brasileiro de Geografia e Estatística (IBGE). De acordo com o censo demográfico, em 2010, Fortaleza tinha população de 2.452.185 habitantes (IBGE, 2010); dados mais atuais revelam uma população composta por 2.571.896 habitantes (IBGE, 2014). Paralelo ao crescimento populacional da cidade, Fortaleza vem sofrendo com a redução de sua cobertura vegetal. Nos anos de 1968 e 2003, o percentual de cobertura vegetal nativa e original era de 65,79 e 7,06\%, respectivamente, conforme dados apontados pelo Inventário Ambiental de Fortaleza (PREFEITURA DE FORTALEZA, 2003).

Como área verde pública de expressividade na cidade de Fortaleza temos o Parque Ecológico do Rio Cocó (Figura 1), mais conhecido como Parque Ecológico do Cocó (ou somente Parque do Cocó). Sob administração estadual, é um dos mais importantes ambientes naturais do estado, tendo ampliado a área já existente do Parque Adahil Barreto; além disso, é considerado pela Superintendência Estadual do Meio Ambiente (SEMACE) um dos maiores parques urbanos do Brasil com ecossistemas naturais.

\section{Coleta e análise de dados}

Foram levantadas informações sobre as áreas verdes públicas urbanas de Fortaleza e sua relação com a meIhoria da qualidade de vida. Entre julho e setembro de 2014, foram feitas visitas ao Parque e aplicados 64 formulários a frequentadores, selecionados de forma aleatória, por meio de uma abordagem direta ao longo da trilha ecológica no turno da manhã.

O formulário era composto de21 questões objetivas contendo: identificação do usuário, suas formas de
O parque foi criado em outubro de 1989, pelo Decreto estadual no 20.253, compreendendo uma área de 1.046 ha (CEARÁ, 1989). Em 8 de julho de 1993, o Decreto no 22.587 declarou de interesse social, para fins de desapropriação, as áreas destinadas à ampliação do parque, perfazendo um total de 1.155,2 ha (CEARÁ, 1993). Porém, até hoje, as propriedades privadas existentes dentro da poligonal proposta à época não foram desapropriadas, impedindo que a questão jurídica de delimitação do parque fosse resolvida. Entretanto, o atual governador do estado do Ceará, Camilo Santana, afirmou que a regulamentação do Parque do Cocó será uma das prioridades do seu mandato. $O$ governador pretende ampliar a área, incorporando a ela trechos que estão sendo urbanizados nas margens do Rio Cocó. Essa área corresponde a cerca de 200 ha, a qual, somada aos $1.312,30$ ha da delimitação proposta em estudo de 2008, elevaria o tamanho do parque para $1.512,30$ ha.

Podem ser identificadas no parque várias unidades geoambientais, como: planície litorânea, planície flúvio-marinha e superfície de tabuleiros litorâneos (CEARÁ, 2010), englobando diversas espécies de vida animal e vegetal. O Parque do Cocó apresenta áreas disponíveis para atividades de lazer, esporte e cultura, contando com anfiteatro, quadras esportivas, pistas para caminhadas e corridas, campos de futebol, entre outros equipamentos.

uso do parque, percepção ambiental e de qualidade de vida, e aspectos socioeconômicos. Cada item foi avaliado em uma escala gradativa de notas de 1 a 5 , sendo " 1 " muito ruim e " 5 " muito bom.

Em um estudo com o objetivo de analisar o conceito de qualidade de vida a partir da percepção dos moradores da cidade de Porto, em Portugal, Santos et al. (2002) definiram três perspectivas de análise para qualidade vida. A primeira tem a ver com a distinção entre os as- 
pectos materiais e imateriais da qualidade de vida, a segunda faz a distinção entre os aspectos individuais e os coletivos, e a terceira faz a distinção entre aspectos objetivos e subjetivos da qualidade de vida. Considerando tais perspectivas em análise de qualidade de vida, o formulário aplicado em campo continha, ainda, um quadro com 35 indicadores, dentre os quais cada entrevistado destacou dez que considerasse os mais importantes para sua boa qualidade de vida. Os indicadores compreendiam campos sociais, políticos, ambientais, pessoais e de serviços básicos. Buscou-se englobar indicadores que integrem os recursos indispensáveis para saúde e qualidade de vida definidos pela Carta de Ottawa; aqueles previstos nos domínios para aferir qualidade de vida avaliados pelo questionário World Health Organization Quality of Life (WHOQOL), da Organização Mundial da Saúde (OMS); e indicadores propostos por Herculano (2000). Alguns indicadores novos, ainda não considerados anteriormente, como "turismo nacional e internacional", "aceitação em redes sociais" e "consu- mo de itens orgânicos", foram incluídos por este estudo a fim de aferir se haveria aderência a eles. Assim, o quadro de indicadores para uma boa qualidade de vida entregue aos usuários do Parque Ecológico do Cocó durante as entrevistas realizadas por este estudo englobou, de forma aleatória, indicadores representativos dessas três perspectivas aplicadas no Porto. Foi possível aferir sobre as abordagens subjetivas da qualidade de vida, via análise individual, valorizando a percepção baseada na experiência pessoal e introspectiva dos usuários do parque.

Com o intuito de evitar certo padrão tendencioso nas respostas obtidas, foram feitas cinco versões do quadro de indicadores, alternando-se, aleatoriamente, a distribuição apresentada. O tempo de aplicação de cada questionário foi em média de 10 a 15 minutos. As respostas sobre percepções acerca da qualidade de vida e indicadores foram trabalhadas em função da frequência de respostas.

\section{Localização do Parque do Cocó em Fortaleza, Ceará}

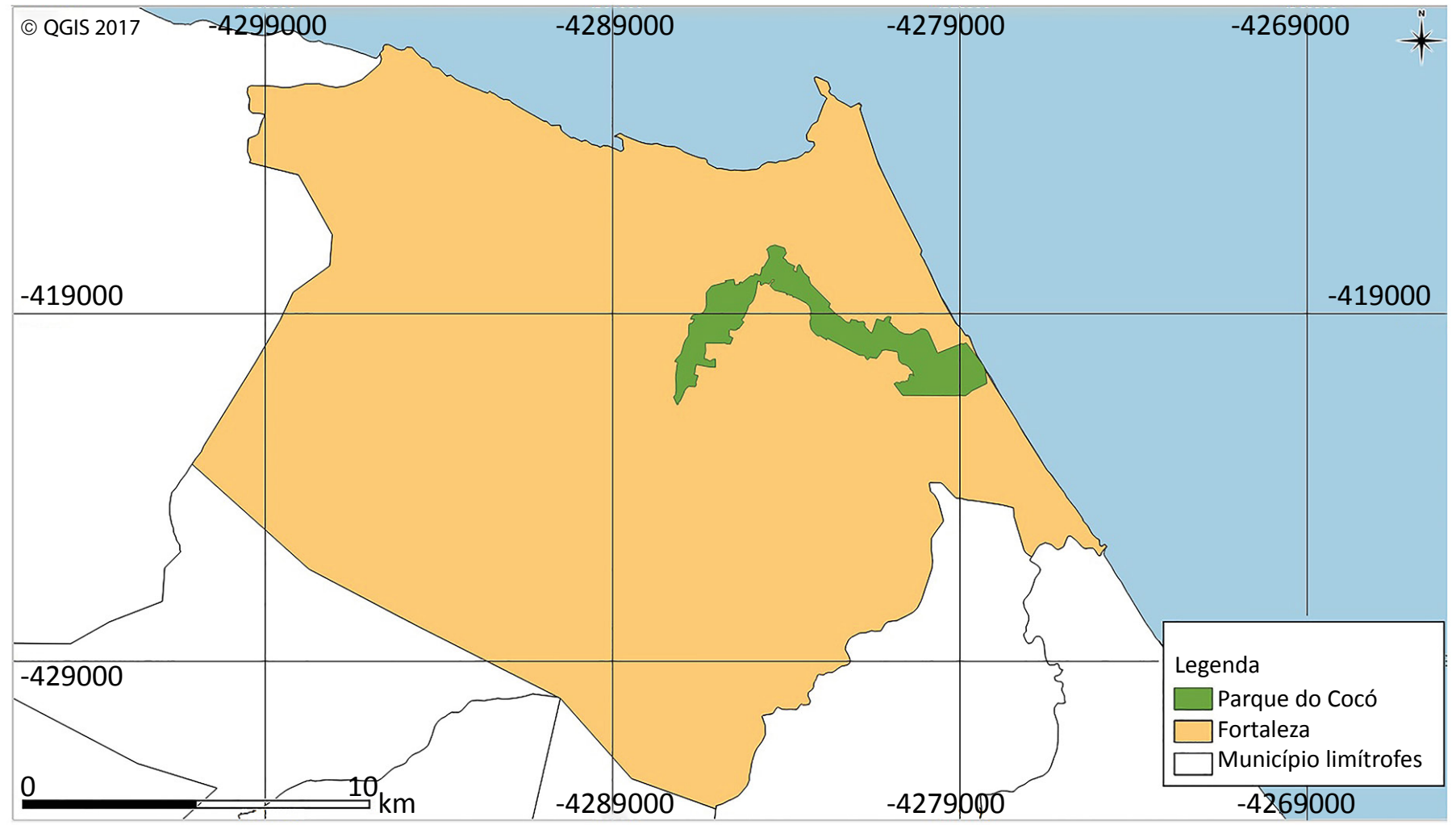

Figura 1 - Área do Parque Ecológico do Rio Cocó. 


\section{RESULTADOS}

Os dez indicadores mais frequentemente citados para descrever uma boa qualidade de vida entre os usuários incluíram necessidades como: "práticas esportivas e atividades físicas"; "segurança pública"; "disponibilidade de parques, praças e áreas verdes"; "contato com a natureza"; "educação de qualidade"; "acesso à água potável"; "sucesso nas relações interpessoais"; "bom convívio familiar"; "realização profissional"; e "moradia adequada" (Figura 2). Dentre os dez indicadores mais citados entre os usuários, dois estão relacionados ao meio ambiente: disponibilidade de parques, praças e áreas verdes, e contato com a natureza. Estes, juntos, representam cerca de $22,0 \%$ das respostas, e ocupam a terceira e a quarta posição entre os mais citados.

Práticas esportivas e atividades físicas

Segurança pública

Parques, praças e áreas verdes

Contato com a natureza

Educação de qualidade

Acesso à água potável

Sucesso nas relações interpessoais Bom convívio familiar

Realização profissional Moradia adequada

Bem-estar psicológico

Compromisso religioso e fé

Condições financeiras satisfatórias

Acesso a serviços de saúde e qualidade

Alimentação balanceada

Acesso a opções culturais, artísticas ou educativas

Boas condições de trabalho

Limpeza urbana

Qualidade do ar

Respeito civil e cumprimento das leis

Trânsito urbano fluente

Transporte público de qualidade

Acesso ao saneamento básico Justiça social

Ambiente ecologicamente equilibrado Bem-estar físico

Liberdade de expressão Opções de lazer

Consumo de itens orgânicos

Turismo nacional

Acesso a tecnologias e bens de consumo

Acesso à internet

Aceitação em redes sociais

Mídia livre

Turismo internacional

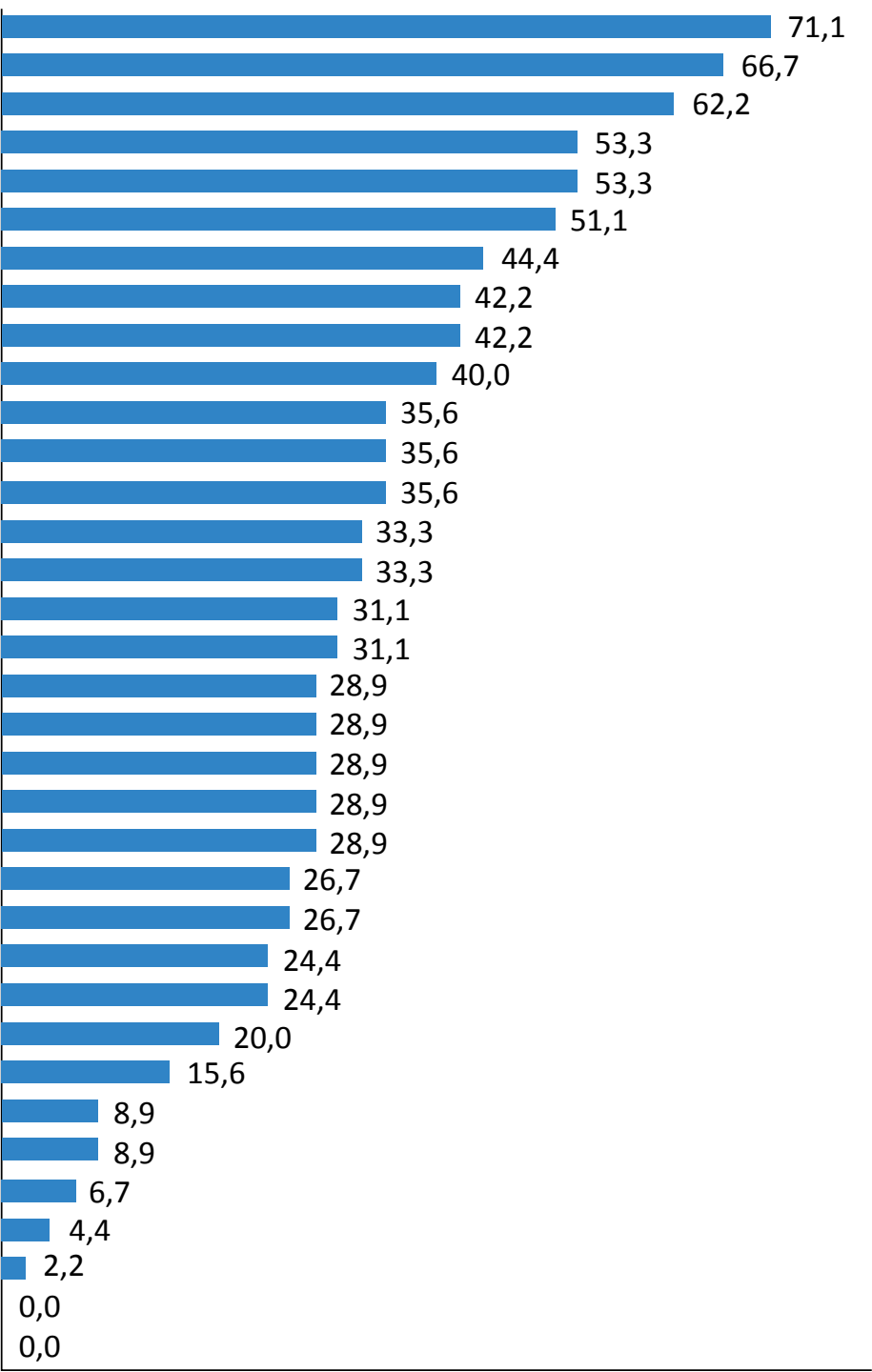

Figura 2 - Frequência relativa dos indicadores selecionados como os mais importantes para uma boa qualidade de vida pelos usuários entrevistados neste estudo. 
Os itens "mídia livre" e "turismo internacional" não foram escolhidos durantes as entrevistas.

Entre os 64 formulários aplicados no Parque do Cocó, foram identificados frequentadores provenientes de 26 bairros de Fortaleza (Aldeota, Barra do Ceará, Castelão, Cidade 2000, Cidade dos Funcionários, Cocó, Conjunto Palmeiras, Dunas, Edson Queiroz, Guararapes, Itaperi, Jardim das Oliveiras, Jardim Iracema, Joaquim Távora, Jóquei Club, José Bonifácio, Luciano Cavalcante, Meireles, Monte Castelo, Papicu, Parque Dois Irmãos, Parquelândia, Passaré, Sapiranga, Padre Andrade e Serrinha) e de uma Região Metropolitana (Eusébio), e usuários de três cidades de outros estados brasileiros (Brasília, Porto Alegre e Minas Gerais). Os usuários - 27 homens e 37 mulheres - tinham entre 16 e 67 anos de idade. O Parque Ecológico do Cocó é utilizado por esse público principalmente para a realização de atividades físicas $(64,0 \%)$, seguida por atividades de lazer $(20,0 \%)$. Outras atividades citadas foram "contemplação da natureza" (12,0\%), "realização de piquenique" (3,0\%), "local para ponto de encontro" (1,0\%). Dos usuários, 58,0\% permanecem, em média, 1 hora no parque, $40 \%$ entre 1 e 2 horas, e apenas $2 \%$, menos de 30 minutos.

Metade dos entrevistados utilizam o parque todos os dias ou semanalmente, e $46,4 \%$ apontaram a falta de tempo como o motivo de não o frequentarem mais, tendo sido afirmado por $95 \%$ das pessoas que, se pudessem, iriam ao local com maior frequência. A maioria dos entrevistados $(88,6 \%)$ frequenta o parque acompanhado por familiares, amigos ou animais de estimação, $e$ apenas $11,4 \%$ deles constumam frequentá-lo sozinhos.
Do total de entrevistados, sete estavam no parque pela primeira vez, mas afirmaram pretender voltar. Todos destacaram que o fato de o Parque do Cocó ser uma uma área verde em zona urbana foi fator determinante para a escolha como local para realização de suas atividades, por contribuir para a melhoria da qualidade de vida. Mais da metade dos entrevistados $(53,1 \%)$ afirmaram não frequentar outras áreas verdes na cidade, e $84,1 \%$ classificaram o número de áreas verdes em Fortaleza como ruim ou precário; apenas $15,9 \%$ dos entrevistados o classificaram como bom, e nenhum o considerou muito bom.

Em relação aos benefícios que costumam sentir e/ou perceber durante o tempo que passam no parque, os usuários destacaram em ordem decrescente de citação: contato com a natureza $(100,0 \%)$; sensação de bem-estar (98,4\%); conforto térmico $(90,6 \%)$; ar mais puro $(89,1 \%)$; som dos pássaros $(85,9 \%)$; conforto sonoro $(85,9 \%)$ e atenuação de ruídos $(60,9 \%)$. Mais da metade dos entrevistados $(57,8 \%)$ já frequentaram uma ou mais vezes algum evento realizado no Parque do Cocó; $21,7 \%$ disseram nunca ter ido, mas afirmaram ter interesse em participar de algum; os outros 19,6\% nunca foram e afirmaram não ter interesse em participar.

De forma geral, aspectos como limpeza, infraestrutura, segurança manutenção e arborização do parque foram classificados pelos usuários entre regular e ótimo, e as notas 3,4 e 5 foram as mais frequentes. 0 aspecto "importância", que se refere ao quão importante o usuário considera o Parque do Cocó para a cidade de Fortaleza, teve por unanimidade a nota máxima (Tabela 1).

Tabela 1 - Frequência de notas para diferentes aspectos do Parque do Cocó dadas pelos usuários entrevistados neste estudo.

\begin{tabular}{|l|c|c|c|c|c|c|c|c|c|c|}
\hline Aspecto & $\begin{array}{c}\text { Nota 1 } \\
\text { (fi) }\end{array}$ & fri & $\begin{array}{c}\text { Nota 2 } \\
\text { (fi) }\end{array}$ & fri & $\begin{array}{c}\text { Nota 3 } \\
\text { (fi) }\end{array}$ & fri & $\begin{array}{c}\text { Nota 4 } \\
\text { (fi) }\end{array}$ & fri & $\begin{array}{c}\text { Nota 5 } \\
\text { (fi) }\end{array}$ & fri \\
\hline Limpeza & 1 & $1,6 \%$ & 7 & $10,9 \%$ & 16 & $25 \%$ & 21 & $32,8 \%$ & 19 & $29,7 \%$ \\
\hline Infraestrutura & 2 & $3,1 \%$ & 5 & $7,8 \%$ & 24 & $37,5 \%$ & 16 & $25 \%$ & 17 & $26,6 \%$ \\
\hline Segurança & 4 & $6,3 \%$ & 11 & $17,2 \%$ & 16 & $25 \%$ & 15 & $23,4 \%$ & 18 & $28,1 \%$ \\
\hline Manutenção & 3 & $4,7 \%$ & 10 & $15,6 \%$ & 24 & $37,5 \%$ & 18 & $28,1 \%$ & 9 & $14,1 \%$ \\
\hline Arborização & 0 & $0,0 \%$ & 1 & $1,6 \%$ & 6 & $9,4 \%$ & 8 & $12,5 \%$ & 49 & $76,6 \%$ \\
\hline Importância & 0 & $0,0 \%$ & 0 & $0,0 \%$ & 0 & $0,0 \%$ & 0 & $0,0 \%$ & 64 & $100 \%$ \\
\hline
\end{tabular}

fi: frequência absoluta; fri: frequência relativa; nota " $x$ ": nota atribuída ao aspecto indagado. 


\section{DISCUSSÃO}

As funções desempenhadas pelas áreas verdes, definidas por Guzzo e Cavalheiro (2000) e Andrade (2010), realizam papel fundamental na amenização de problemas socioambientais decorrentes da degradação dos sistemas naturais. Tais funções estão sendo desempenhadas pelo Parque Ecológico do Rio Cocó, observadas a partir dos resultados obtidos por este estudo. Além disso, podemos considerar o Parque do Cocó a herança cultural e ecológica mais importante da cidade de Fortaleza.

A literatura científica aborda inúmeras contribuições dos benefícios proporcionados pela arborização no meio urbano atribuídas à composição de sua fauna e flora, ao solo não impermeabilizado, e às funções e serviços ecossistêmicos prestados, como: redução da poluição do ar por meio de processos de oxigenação e ação purificadora por fixação de poeiras e materiais residuais; conservação da umidade dos solos, filtração da radiação solar, suavizando as temperaturas extremas; e amortecimento dos ruídos de fundo sonoro contínuo e descontínuo de caráter estridente. Não foi objetivo deste estudo identificar cada uma das funções ecológicas desempenhadas pelo Parque do Cocó; buscou-se, porém, a percepção dos usuários sobre os benefícios destacados, que pôde ser avaliada por meio das entrevistas. Entre os benefícios sentidos e/ou percebidos durante o tempo de permanência no parque, "conforto térmico", "ar mais puro" e "conforto sonoro" apresentaram três das seis maiores frequências de citação. Tais benefícios são oriundos da função ecológica desempenhada pelo Parque do Cocó, mas também acabam contribuindo no desempenho da função psicológica, visto que, durante o tempo que permanecem no parque, os usuários estão sob condições térmicas e sonoras menos estressantes. Embora não tenha sido avaliada durante as entrevistas, não podemos deixar de ressaltar a importância do ecossistema manguezal que compõe boa parte da área do Parque do Cocó. Os manguezais são ecossistemas dinâmicos e frágeis, que estão entre os maiores produtores de matéria orgânica e desempenham diversas funções e serviços ambientais, como: proteção contra enchentes; proteção e controle contra erosão; proteção e controle contra salinização de lençóis freáticos; habitat e suporte a atividades de subsistência de comunidades tradicionais; produção de oxigênio; influência nos climas lo- cais e no clima global, entre outros, o que aumenta a relevância da sua preservação.

A importância associada aos benefícios de regulação de temperatura torna-se mais significativa quando tratamos de uma cidade de clima tropical e em constante expansão populacional como Fortaleza. Um estudo realizado por Branco et al. (2012), com o objetivo de analisar o clima em áreas verdes de Fortaleza, apontou que o Parque do Cocó, em comparação com outras áreas verdes da cidade - como a do Campus do Pici, Passeio Público e Parque Pajeú - , foi a área que apresentou as menores temperaturas, 25,6 a $26,6^{\circ} \mathrm{C}$ (período chuvoso) e 24,9 a $26,9^{\circ} \mathrm{C}$ (período seco), em suas áreas internas e externas, respectivamente. Rocha (2014) avaliou indicadores ambientais físicos, químicos e biológicos para a qualidade ambiental de locais utilizados pela população fortalezense para a prática de atividades físicas e lazer. $O$ estudo revelou ser fundamental a implantação de áreas verdes urbanas para a mitigação de problemas relacionados a desconforto térmico, ruídos e, também, material particulado em suspensão.

Já a função social está agregada às diversas possibilidades de lazer, opções culturais e artísticas, práticas esportivas, ou qualquer outra atividade que promova a socialização, ofertadas à população. De fato, como resultado das entrevistas, o Parque do Cocó é utilizado pela maioria das pessoas para práticas de atividades físicas, mas mais da metade já participou de algum evento de caráter cultural, artístico ou comemorativo realizado no espaço. Porém, o número de eventos promovidos pela prefeitura de Fortaleza no local vem diminuindo notoriamente, o que causa impacto direto nas opções de lazer da população. Outras opções de lazer observadas atualmente no parque estão relacionadas, em sua maioria, aos equipamentos dos parques infantis, à realização de piquenique, à trilha ecológica e aos campeonatos ou jogos amistosos promovidos nos campos de futebol e quadras, organizados pelos próprios moradores da região.

A função estética do Parque do Cocó está relacionada ao embelezamento da paisagem urbana, incorporando novas cores e contrastes à cidade de Fortaleza. A função estética é tão significativa que acaba valorizando a área ao seu redor. Atualmente, o metro 
quadrado no bairro Cocó, por exemplo, é um dos mais caros da cidade de Fortaleza (em setembro de 2016 , custava cerca de $\mathrm{R} \$ 6.622,00 / \mathrm{m}^{2}$ ). No entanto, podemos observar certa contradição envolvendo a valorização estética das áreas verdes, visto que a especulação imobiliária é um dos grandes vilões da degradação desses sistemas. Existe uma relação decrescente quanto à oferta de área verde disponível e a demanda de construções ao redor do parque. Desde a sua criação, em 1989, o Parque do Cocó vem perdendo área tanto para o capital imobiliário, quanto para a construção de avenidas e, mais recentemente, viadutos. Em 2013, ambientalistas, militantes e pessoas da sociedade civil ocuparam o Parque do Cocó em protesto contra o desmatamento de uma área para a construção de viadutos. A ocupação durou 80 dias e foi bastante noticiada pelos veículos de comunicação. Porém, terminou de forma violenta: os ocupantes foram tirados à força pelo batalhão de choque da Polícia Militar do Ceará (PMCE) com balas de borracha e gases de efeito moral. Hoje em dia, as obras dos viadutos foram concluídas e estes se encontram em funcionamento, mas a ocupação de 2013 representou um marco histórico nos movimentos em defesa do Parque Ecológico do Cocó.

A função psicológica é percebida pelos usuários do parque por meio da interação com os elementos naturais das áreas verdes; pessoas em contato com o ambiente natural se sentem relaxadas. A sensação de bem-estar mental e contato com a natureza foram os benefícios mais citados. Podemos considerar que a busca da função psicológica figura entre os principais motivos que levam os usuários a frequentar o Parque do Cocó. Na percepção dos usuários, talvez, outros lugares disponíveis para a realização das mesmas atividades não propiciem a mesma sensação de bem-estar que pode ser sentida no Parque do Cocó, já que mais da metade dos entrevistados não frequentam outras áreas verdes da cidade. Também é importante salientar que a função psicológica obtida pelo acesso aos parques urbanos traz benefícios à saúde pública, pois atua como um antiestressante para a população.

Por fim, a função educativa do Parque do Cocó é desempenhada por escolas que usam a área para a realização de aulas de campo ao longo da trilha ecológica, e pelos serviços de guia oferecidos. Os resultados mostraram que existe uma consciência ambiental por parte dos usuários entrevistados quanto à concordância da contribuição das áreas verdes para a melhoria da qualidade de vida. Assim, é importante implementar e difundir programas de educação ambiental que venham somar a essa consciência como instrumento essencial à preservação do parque e de demais áreas verdes, de forma geral.

É válido ressaltar que a magnitude das funções desempenhadas pelas áreas verdes nas cidades está intrinsecamente ligada à quantidade, à qualidade e à distribuição delas nos centros urbanos. Os usuários entrevistados representam uma parcela da população e de visitantes de Fortaleza e, em sua maioria, classificaram o número de áreas verdes na cidade como "ruim" ou "precário" - um resultado preocupante que nos leva questionar a forma de distribuição da cobertura vegetal na cidade. Os estudos dos sistemas de áreas verdes, nos últimos anos, vêm sendo conduzidos no âmbito da questão ambiental urbana, de modo que contribuem para a melhoria da qualidade ambiental das cidades e, consequentemente, para a melhoria da qualidade de vida da sua população. A importância das áreas verdes para a qualidade ambiental foi trabalhada por Lima (2007) na cidade de Osvaldo Cruz, São Paulo, revelando o não cumprimento de sua finalidade em razão da inadequação à lei de parcelamento do solo e até mesmo à ausência de vegetação. Mais recentemente, no Nordeste, Andrade (2010) analisou sistemas de áreas verdes e a relação com a qualidade de vida, na cidade de Sousa, na Paraíba. O estudo de Andrade (2010), quanto à concordância das definições de qualidade de vida, verificou que elementos como "bons relacionamentos sociais", "bons serviços e infraestrutura urbana", "ambiente saudável e agradável", dentre outros, apresentam-se da mesma forma para a sociedade.

Assim como nos estudos mencionados, no quadro de indicadores, aplicado com os formulários de pesquisa aos usuários do Parque do Cocó, observamos que, atrelados a fatores econômicos, aspectos relacionados ao meio ambiente e sua qualidade estão se destacando e ganhando espaços cada vez maiores, principalmente quando a meta envolve a melhoria da qualidade de vida.

Os resultados do estudo desenvolvido por Santos et al. (2002) também mostraram que a maioria dos entrevistados (cerca de $80,0 \%$ ) invocaram aspectos relacio- 
nados ao meio ambiente, como disponibilidade de espaços verdes, limpeza urbana e ausência de poluição, como os mais relevantes para que uma cidade tenha boa qualidade de vida. Isso mostra uma considerável associação do conceito de qualidade de vida com a natureza que, nas cidades, pode ser representada pelos sistemas de áreas verdes urbanas.

"Práticas esportivas e atividades físicas" foi o indicador mais citado e também o tipo de atividade mais realizada no parque. Esse indicador está diretamente ligado a questões de saúde e bem-estar físico, colocando aspectos individuais da esfera subjetiva no topo das prioridades para que se tenha uma boa qualidade de vida. Logo, podemos observar que o Parque Ecológico do Cocó representa para os entrevistados o objeto mediador capaz de proporcionar a satisfação de três das dez principais necessidades para uma boa qualidade de vida. Os demais indicadores ("sucesso nas relações interpessoais", "bom convívio familiar" e "realização profissional") também representam concepções de subjetividade do indivíduo; "segurança pública", "educação de qualidade", "acesso à água potável" e "moradia adequada" representam parâmetros objetivos. Assim, o resultado dos dez indicadores mais citados revela o peso que a esfera subjetiva tem para as pessoas de Fortaleza na definição de qualidade de vida.
Conforme divulgado pelos resultados da aplicação do WBB na cidade de São Paulo, entre os 10 indicadores estudados e suas 68 variáveis, o indicador "meio ambiente" apresentou-se em sétimo lugar entre os indicadores avaliados em relação aos níveis de satisfação mais próximos dos níveis de relevância para a vida do entrevistado (DA SILVA et al., 2013). Isso nos mostra que o conceito de qualidade de vida para a população e para pesquisadores está cada vez mais buscando pontos comuns. Vale destacar que este estudo incluiu indicadores ainda não citados em outros estudos, como "consumo de itens orgânicos", "aceitação em redes sociais", "turismo nacional" e "turismo internacional". Entre estes, apenas "turismo internacional" e "mídia livre" não foram citados entre as respostas obtidas dos usuários do Parque do Cocó.

A discussão dessas questões é importante para a qualidade de vida urbana e pode ser um elemento adicional no apoio às tomadas de decisão quanto a estratégias e prioridades de ações do poder público. Vale ressaltar que a cidade de Fortaleza é composta de uma população que anseia usufruir de espaços verdes para a prática esportiva e de lazer. Enquanto os governantes não enxergarem a importância das áreas verdes públicas como elementos estruturadores do espaço urbano, a sociedade continuará demandando locais que preencham as lacunas ambientais e sociais.

\section{CONCLUSÃO}

A demanda por áreas verdes é imensa em Fortaleza, pois a cidade apresenta um índice de arborização estimado, atualmente, em $8 \mathrm{~m}^{2}$ de área verde por habitante, um dos menores entre as capitais brasileiras. O número evidencia a precariedade de massa verde na cidade, estando bem abaixo do índice considerado o ideal pela Sociedade Brasileira de Arborização Urbana (SBAU), de $15 \mathrm{~m}^{2}$ de área verde por habitante.

As entrevistas realizadas com os usuários do Parque Ecológico do Rio Cocó confirmaram, por meio da percepção ambiental, a importância dada por habitantes de centros urbanos para o papel das áreas verdes na atribuição de uma boa qualidade de vida. Evidenciando que os espaços verdes são indispensáveis à construção da estrutura da cidade e à integração de espaços de convivência, de práticas de atividades físicas e de lazer, o Parque Ecológico do Cocó desta- cou-se, entre as demais áreas verdes, como a mais almejada dentro da estrutura urbana de Fortaleza. Fica evidente que oferecer espaços ambientalmente saudáveis para a população significa investimento em qualidade de vida. As praças e os parques públicos não devem ser vistos somente como elementos decorativos, mas como um componente físico da paisagem urbana; quando bem projetados e mantidos, são espaços que humanizam o bairro e melhoram a qualidade de vida dos moradores locais.

No contexto de gestão ambiental compartilhada entre governo e sociedade, considerar a percepção da população sobre os problemas e ações governamentais nos processos de tomada de decisões aproxima os gestores das realidades sociais locais. A percepção popular aponta, ainda, deficiências existentes no modelo de gestão ambiental, como a insatisfação dos 
entrevistados quanto ao número de áreas verdes na cidade de Fortaleza revelada por este estudo. A má distribuição (ou mesmo inexistência) de áreas verdes urbanas compromete diretamente a magnitude das funções ecológicas, sociais, estéticas, psicológicas e educativas que podem ser desempenhadas e ofertadas à população. Consequentemente, afeta a qualidade de vida percebida e vivenciada pelas pessoas em grandes centros urbanos, como é o caso na cidade de Fortaleza.

\section{REFERÊNCIAS}

ALMEIDA, M. A. B.; GUTIERREZ, G.L.; MARQUES, R. Qualidade De vida: definição, conceitos e interfaces com outras áreas de pesquisa. São Paulo:EACH/USP,2012.142 p.

ALVES, T. C. V. A. Parques Urbanos de Fortaleza - CE: espaço vivido e qualidade de vida.199 p. Tese (Doutorado em Geografia) -Universidade Estadual Paulista "Júlio de Mesquita Filho", Rio Claro, 2013.

ANDRADE, D. P. X. de. Sistemas de áreas verdes e percepção de qualidade de vida na cidade de Sousa - PB. 173 p. Dissertação (Mestrado em Engenharia Urbana) - Universidade Federal da Paraíba, João Pessoa, 2010.

BARGOS, D. C.Mapeamento e análise das áreas verdes urbanas como indicador da qualidade ambiental urbana:estudo de caso de Paulínia-SP. 147 f. Dissertação (Mestrado em Geografia) -Instituto de Geociências, Universidade Estadual de Campinas, Paulínia, 2010.

BRANCO, K. G. C.; ZANELLA, M. E.; SALES, M. C. L. O clima em áreas verdes intra-urbanas de Fortaleza. Revista Geonorte, ed. especial 2, v.2, n. 5, p.443-454, 2012.

. Resolução Conama n.o 369, de 28 de março de 2006. Dispõe sobre os casos excepcionais, de utilidade pública, interesse social ou baixo impacto ambiental, que possibilitam a intervenção ou supressão de vegetação em Área de Preservação Permanente APP. 2006. Disponível em: <http://www.mma.gov.br/port/conama/legiabre. cfm?codlegi=489>. Acesso em: 6 mar. 2014.

CEARÁ. Decreto n.o 20.253, de 5 de setembro de 1989. Declara de interesse social para fins de desapropriação as áreas de terra que indica e dá outras providências. Diário Oficial do Estado, 1989. Disponível em: <http://antigo.semace. ce.gov.br/biblioteca/legislacao/conteudo_legislacao.asp?cd=161>. Acesso em: nov. 2014.

. Decreto n. 22.587, de 8 de junho de 1993. Declara de interesse social, para fins de desapropriação as áreas que indica e dá outras providências.Diário Oficial do Estado,1993. Disponível em: <http://antigo.semace.ce.gov.br/ integracao/biblioteca/legislacao/conteudo_legislacao.asp?cd=162>. Acesso em: nov. 2014.

Superintendência Estadual do Meio Ambiente (SEMACE). Parque Ecológico do Rio Cocó. 2010. Disponível em: <http://www.semace.ce.gov.br/2010/12/paque-ecologico-do-rio-coco/>. Acesso em: 7 mar. 2014.

DA SILVA, W. M.; GARCIA, F. G.; MOTORYN, M. Survey Well Being Brasil -Cidade de São Paulo. Fundação Getúlio Vargas. São Paulo, 30 de novembro de 2013. Disponível em: <http://ag.taxi.br/projetos/myfuncity/WBB_RELATORIO_SP.pdf >. Acesso em: 27 de março de 2017.

GUZZO, P. Estudo dos espaços livres de uso público da cidade de Ribeirão Preto/SP, com detalhamento da cobertura vegetal e áreas verdes públicas de dois setores urbanos. 125 p. Dissertação (Mestrado em Geociências) - Instituto de Geociências e Ciências Exatas, Universidade Estadual Paulista, Rio Claro, 1999.

GUZZO, P.; CAVALHEIRO, F. Disponibilidade de espaços livres de uso público em Ribeirão Preto, SP. In: FÓRUM DE DEBATES ECOLOGIA DA PAISAGEM E PLANEJAMENTO AMBIENTAL, 1., 2000, Rio Claro. Anais... 2000. 
HERCULANO, S. C.A qualidade de vida e seus indicadores. In: HERCULANO, S. C.; PORTO, M. F. S.; FREITAS, C. M. (Orgs.). Qualidade de vida e riscos ambientais.Niterói: EDUFF, 2000.p. 219-246.

HERCULANO, S. C.; PORTO, M. F. S.; FREITAS, C. M. (Orgs.). Qualidade de vida e riscos ambientais.Niterói: EDUFF, 2000. 334 p.

INSTITUTO BRASILEIRO DE GEOGRAFIA E ESTATÍSTICA (IBGE). IBGE divulga as estimativas populacionais dos municípios em 2014. 2010. Disponível em: < http://cidades.ibge.gov.br/xtras/perfil.php?codmun=230440>. Acesso em: nov. 2014.

. IBGE divulga as estimativas populacionais dos municípios em 2014.2014. Disponível em: <http://saladeimprensa. ibge.gov.br/noticias?view=noticia\&id=1\&busca=1\&idnoticia=2704>. Acesso em: nov. 2014.

LIMA, V. Análise da qualidade ambiental na cidade de Osvaldo Cruz/SP. 146 p. Dissertação (Mestrado em Geografia) - Universidade Estadual Paulista "Júlio de Mesquita Filho", Presidente Prudente, 2007.

LOBODA, C. R.; DE ANGELIS, B. L. D. Áreas verdes públicas urbanas: conceitos, usos e funções.Ambiência, v.1, n.1, p. 125-139, jan./jun. 2005.

PREFEITURA DE FORTALEZA. Secretaria Municipal de Urbanismo e Meio Ambiente (SEUMA). Coordenadoria de Políticas Ambientais (CPA). Política ambiental de Fortaleza. Fortaleza, 2013. 64 p. Disponível em: <http://www.fortaleza.ce.gov. $\mathrm{br} / \mathrm{sites} /$ default/files/politica_ambiental_de_fortaleza.pdf>. Acesso em: jun. 2014.

ROCHA, C. A. Pressão sonora, sensação térmica, poluição do ar e seus riscos associados como indicadores da qualidade ambiental em áreas usadas para esporte e lazer - Fortaleza, CE.79f. Monografia (Graduação em Ciências Ambientais) - Instituto de Ciências do Mar,Universidade Federal do Ceará, Fortaleza,2014.

RODRIGUES, M. L.; MALHEIROS, T. F.; FERNANDES, V.; DAGOSTIN DAROS, T. A percepção ambiental como instrumento de apoio na gestão e na formulação de políticas públicas ambientais.Saúde e Sociedade,São Paulo, v. 21, p. 96-110, jun. 2012.

SANTOS, L. D.; MARTINS, I.; BRITO, P. - O conceito de qualidade de vida urbana na perspectiva dos residentes na cidade do Porto. Revista Portuguesa de Estudos Regionais. n. 9, 2005. 